\title{
Atmospheric circulation patterns associated with strong wind events in Catalonia
}

\author{
J. C. Peña, M. Aran, J. Cunillera, and J. Amaro \\ Meteorological Service of Catalonia (SMC), C/Berlin, 38-46, CP 08029, Barcelona, Spain
}

Received: 18 June 2010 - Revised: 30 September 2010 - Accepted: 16 November 2010 - Published: 13 January 2011

\begin{abstract}
The benefit of having a daily synoptic weather type catalogue and even more, a detailed catalogue for high impact weather events is well recognised by both climatologist and meteorologist communities. In this way the Meteorological Service of Catalonia (SMC) has produced some accurate classifications for extreme events, such as hailstorms or strong winds (SW). Within the framework of the MEDEX project, the SMC has been collaborating to increase the level of awareness about these events. Following this line of work, the aim of this study is to characterise the SW events in Catalonia.

According to the guidelines of the MEDEX project we worked with its SW event database for the period June 1995 to May 2004. We also used the period 2005-2009 to test the methodology. The methodology is based on principal component, cluster and discriminant analyses and applied to four variables: SLP, temperature at $850 \mathrm{hPa}$ and geopotential at $500 \mathrm{hPa}$ on a synoptic-scale and local gust wind. We worked with ERA-Interim reanalysis and applied discriminant analysis to test the quality of the methodology and to classify the events of the validation period.

We found seven patterns for the SW events. The strongest event corresponds to NW-Flow with the Azores Anticyclone and the passing of a low pressure through the Pyrenees. This methodology has distinguished the summer events in an independent cluster. The results obtained encourage us to follow this line of work.
\end{abstract}

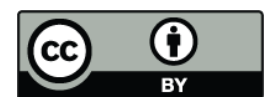

Correspondence to: J. C. Peña (jcpena@meteo.cat)

\section{Introduction}

Catalonia, situated in the Northeast of the Iberian Peninsula, is a region of complex relief. In the North it is delimited by the Pyrenees range (mean average height of $1800 \mathrm{~m}$ ) and from Northeast to Southwest by the Mediterranean Sea coast and the Prelitoral range. Inland, the region is open along the Ebro valley (Fig. 1b). This orography strongly modulates the general flow of wind. The influence of the Pyrenees on the local wind regime was studied during the PYREX experiment (Bougeault et al., 1997). It was proved that the synoptic flow is dynamically adapted to the presence of this range (Campins et al., 1995; Bénech et al., 1998) but its response, direction and speed depend on the synoptic wind itself. Another factor that contributes to the different wind regimes in this region is its situation at mid-latitudes. Thus, it can be affected by the passage of polar lows and, although less frequently, by subtropical ones. Strong wind events in the Mediterranean Sea have lately been studied within the framework of the MEDEX - MEDiterranean EXperiment on cyclones project (http://medex.aemet.uib.es/) (Campins et al., 2006, 2007). From another point of view, requests for damages received at the Meteorological Service of Catalonia (SMC) show that the impact on society is higher for strong wind events than for heavy rain events (Gayà et al., 2008; Amaro et al., 2009b). Recently, on the 24 January 2009, an explosive cyclogenesis took place in the Atlantic. This windstorm pounded the North of Spain and the South of France with some casualties and important economic losses (Amaro et al., 2009a). Moreover, in some wind events the synergy with a heavy rain event increases the magnitude of the phenomena and risk perception (Amaro et al., 2009a). Consequently, it is necessary to build a wind synoptic classification in order to characterise and improve the forecast of these events. 


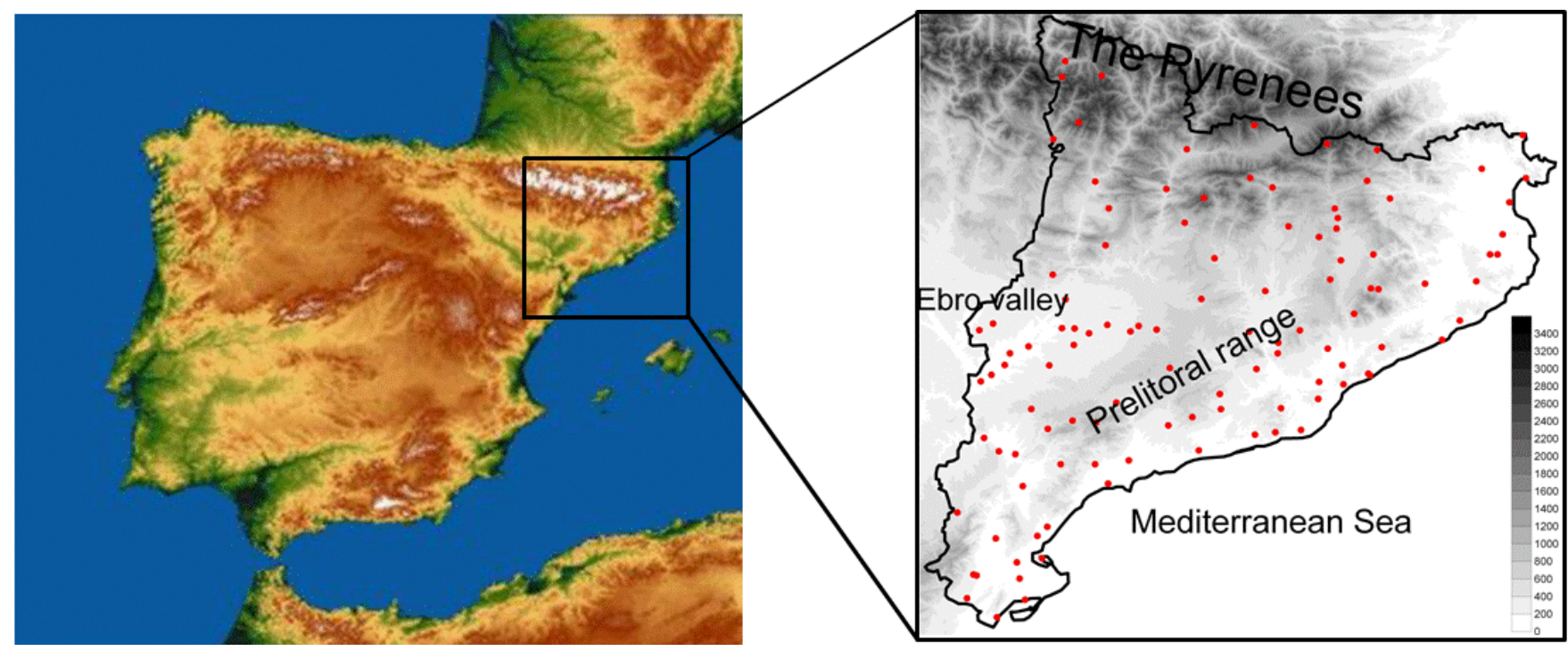

Fig. 1. (a) Iberian Peninsula; (b) Catalonia, red dots are SMC automatic weather stations.

Some other aspects of the synoptic scale circulation influence on local climate are analysed by Cassano et al. (2006). The importance of identifying and cataloguing the atmospheric flows that affect a region, not only for meteorology and climatic aspects, but also for monitoring pollution episodes or making good use of wind energy cannot be underestimated (Beaver and Palazoglu, 2009).

Several studies have been made in relation to the atmospheric flows and their application to wind energy (Palutikof et al., 1987). There have been more numerous studies regarding the transportation of contaminants and the identification of those flows that originate it. At the beginning, they used the synoptic subjective catalogues to identify the principal atmospheric trajectories that affected a region. It was not since the mid-eighties of the last century with the pioneer works of Moody (1986) and Moody and Galloway (1988) that objective techniques such as multi-variant analysis to identify and catalogue the trajectories were applied, in particular using cluster analysis (CA). Subsequently, applying a similar methodology, Ávila and Alarcón (1999) identified the principal trajectories that could be susceptible to danger for the Iberian Peninsula. Later, Jorba et al. (2004) used the same methodology for the metropolitan area of Barcelona. Finally, Gallero et al. (2006) identified the principal trajectories in relation to contaminant transport in the Strait of Gibraltar, off the southern Iberian Peninsula. From another point of view and following this line of work, different authors have created various climatologies of dominant wind patterns in a region. We want to emphasise two studies that are based on multivariate analysis techniques applied at regions with an intricate topography. The first one was constructed for Switzerland (Weber and Furger, 2001). It is based on the classification of wind data from 115 automatic weather sta- tions (AWS). They manage to identify 16 wind patterns applying a CA in two stages: a hierarchical accumulative cluster analysis in the first stage and an non-hierarchical K-means analysis in the second stage to refine the groups obtained in the first step. The second is applied by Jiménez et al. (2009) for the Northeast of the Iberian Peninsula. They apply the same methodology but they also include a temporary regionalisation of win data from 41 AWS applying a principal component analysis (PCA) in S Mode to compare the results between both methodologies.

Both studies are focused on associating synoptic wind patterns with a particular meteorological variable (temperature, precipitation, radiation and wind direction and velocity). However, they do not specifically identify synoptic situations for strong wind events, which are usually the ones with the highest social impact (Amaro et al., 2009b). Few studies have been done to solve this problem with the generation of a specific catalogue that explains the relationship between the atmospheric circulation and this extreme event. It is worth mentioning the study of Cassano et al. (2006) which identified the synoptic patterns causing strong wind in Alaska using a methodology based on a neuronal network algorithm, known as Self-Organizing Map technique created by Kohonen (2001). This algorithm treats data as a continuum and has the advantage of identifying the local synoptic circulation climate. However, multivariate analysis techniques are widely accepted by researchers to elaborate synoptic catalogues (Huth et al., 2008). There is also an important line of research that uses these techniques to look for some relationship between atmospheric patterns and extreme meteorological events, such as heavy rainfall (Houssos et al., 2008; Martín Vide et al., 2008; Martínez et al., 2008; Vicente Serrano et al., 2009), extreme summer temperatures and heat 
Table 1. Annual distribution of the strong wind events and percentage of AWS wind data.

\begin{tabular}{ccc}
\hline Year & $\begin{array}{c}\text { Number of strong } \\
\text { wind events }\end{array}$ & $\begin{array}{c}\text { Percentage (\%) } \\
\text { of wind data }\end{array}$ \\
\hline 1996 & 1 & 56 \\
1997 & 20 & 64 \\
1998 & 72 & 85 \\
1999 & 93 & 91 \\
2000 & 83 & 97 \\
2001 & 84 & 98 \\
2002 & 90 & 98 \\
2003 & 83 & 97 \\
2004 & 43 & 96 \\
\hline
\end{tabular}

waves (García Herrera et al., 2005; Kyselý and Huth, 2008), heavy snow and variability in snow cover (Esteban et al., 2005; López Moreno and Vicente Serrano, 2007), and extreme episodes of avalanches (García et al., 2009). These studies both use multivariate statistics like PCA, CA or both methods simultaneously (Esteban et al., 2006).

The potential of the PCA and CA techniques has encouraged us to build a synoptic catalogue explaining the relationship between atmospheric circulation and strong wind events in Catalonia. Section 2 gives details of data used. Section 3 explains and justifies the methodology applied; Sect. 4 examines the results. Finally, in Sect. 5 we will present our conclusions and topics for discussion.

\section{Data}

As a contribution to the knowledge of hazardous events in the Mediterranean region and within the framework of the MEDEX project, this study was carried out using the MEDEX data base that includes the period June 1995 to May 2004 (available online at http://medex.aemet.uib.es/). A strong wind event is defined by the MEDEX project as one day when wind gust in an AWS overcomes $25 \mathrm{~m} \mathrm{~s}^{-1}$ or $33 \mathrm{~m} \mathrm{~s}^{-1}$ for elevated stations (more than $1800 \mathrm{~m}$ ). This study is only focused on the Catalonian region and it uses the AWS data only available from the Servei Meteorològic de Catalunya (SMC).

The annual amount of wind data available from AWS is variable, mainly for the Medex period. We have to discard 1995 because there is not enough data. Since 1996 there is nearly $60 \%$ of wind data of all the stations (107). From 1999 onwards, there is more than $90 \%$ of wind data available. The number of strong wind events detected in the whole period (1996-2004) is 569 days; once more, the low number of AWS and their geographic distribution determine the number of strong wind events (Table 1). As a further step to verify the robustness of the statistical technique used, led us to use

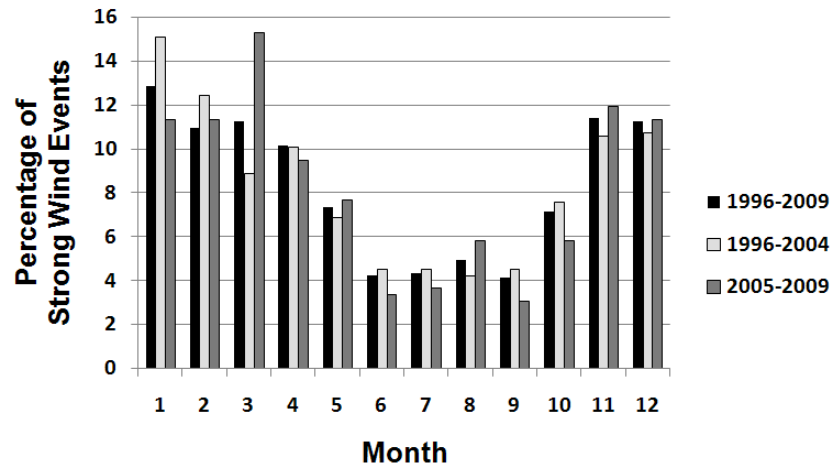

Fig. 2. Monthly distribution of the Strong Wind Events for the periods studied (in bars) and a polynomial adjust for the total period 1996-2009.

wind data for the period 2005-2009 as well. In this last period, there were 327 strong wind events.

Figure 2 shows the monthly distribution of the strong wind events in Catalonia for the whole series: the MEDEX period (1996-2004) and the validation period (2005-2009). Strong wind events are more frequent in winter and $45 \%$ of the events happen between November and February. On the contrary, in summer the number of cases is reduced to only $15 \%$. The monthly distributions of the MEDEX period and the validation period have slight differences which are not significant for our purposes.

On the other hand, two different reanalyses were tested. The first one was NCAR-NCEP at $2.5^{\circ}$ grid resolution. As a first step, the methodology was applied to two geographical domains: the western-Mediterranean domain $\left(30^{\circ} \mathrm{N}-48^{\circ} \mathrm{N}\right.$; $\left.9^{\circ} \mathrm{W}-15^{\circ} \mathrm{E}\right)$ and a synoptic domain $\left(30^{\circ} \mathrm{N}-70^{\circ} \mathrm{N} ; 30^{\circ} \mathrm{W}-\right.$ $\left.20^{\circ} \mathrm{E}\right)$ centred in South England. The results showed that the small domain was not suitable for discerning the synoptic situations when the main low and high centres were out of the domain. Furthermore, the synoptic domain resolved the main situation better for each season (Aran et al., 2009). The next step was to carry out some proofs with ERA-Interim reanalysis for the synoptic domain. We obtained better results and this encouraged us to redo the work using this other reanalysis. The ERA-Interim reanalysis is an improvement on the ERA-40 reanalysis because it has a higher resolution (horizontal-1.5 $5^{\circ}$ and vertical-37 levels). What is more, it has improved the atmospheric model and assimilation system (Simmons et al., 2007). This dataset is available on line from 1989 onwards (http://data-portal.ecmwf.int/data/d/ interim_daily/).

\section{Methodology}

A good methodology should take into account the complex topography, the climatic variability that characterises Catalonia, the occurrence of extreme events, their 


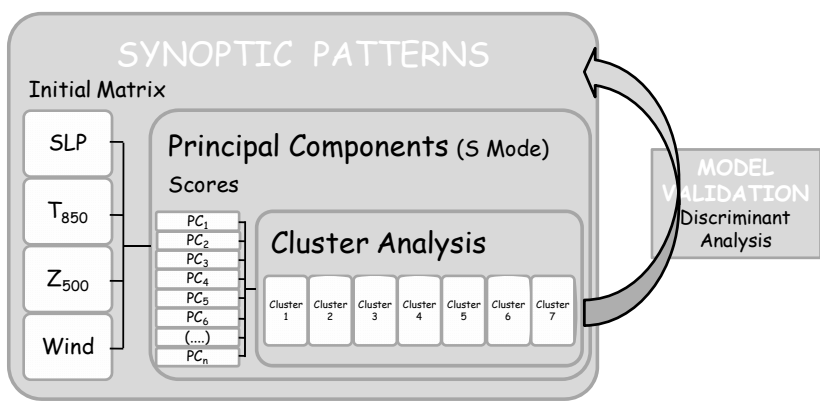

Fig. 3. Diagram of the methodology used.

relationship and connection with atmospheric circulation patterns. Also, it has to be useful to assist both the research and operational weather forecasting of extreme events. For all these reasons, we used multivariate analysis techniques in order to make a catalogue of atmospheric circulation patterns to explain the strong wind situations in Catalonia. With this method we got atmospheric circulation patterns independent of each other and we also synthesised the complex relationships between atmospheric circulation and climate variability (López-Moreno and Vicente-Serrano, 2007). On the other hand, it has to be able to explain variations in atmospheric flows when they interact with a topographically complex area such as the northeast of the Iberian Peninsula, producing significant changes in short distances, as indicated by several authors in the analysis of other extreme events (Gonzalez-Hidalgo et al., 2008; Martin-Vide et al., 2008; Vicente-Serrano et al., 2009; Garcia et al., 2009).

In Sect. 3.1 we will see in detail the methodology used to make a synoptic catalogue for strong wind events. This methodology is structured in three stages (Fig. 3). The first two steps are aimed at obtaining a first classification. They are based on reducing the dimensionality of the data set and CA to obtain the classification as several authors have proposed (Richman, 1986; Yarnal, 1993; Esteban et al., 2005, 2006, 2009; Pineda et al., 2008). The third step includes a Discriminant Analysis (DA) with the objective of validating the results obtained (Aran et al., 2010). Moreover, given the complexity of atmospheric processes that produce strong wind events and the complex topography of Catalonia, which can intensify this phenomenon, we have adapted the methodology to consider both synoptic and mesoscale factors. Therefore, to consider weather variability, several atmospheric levels has been chosen: mean sea level pressure (SLP), temperature at $850 \mathrm{hPa}(\mathrm{T} 850)$ and geopotential at $500 \mathrm{hPa}$ (Z500) (Martínez et al., 2008; Houssos et al., 2008; Aran and Peña, 2009; Aran et al., 2010). With regard to the complex topography, we have included a matrix of the scalar wind gust values measured with the AWS which manages the SMC (Aran et al., 2009).
In Sect. 3.2, it is explained how to classify a strong wind for the validation period according to the results obtained previously in Sect. 3.1 of the reference catalogue. In other words, we have applied the component score coefficient matrix obtained from PCA analysis and Fisher's linear discriminant functions of the DA analysis obtained from the proposed methodology to classify the strong wind events of the validation period.

The main goal of applying this double process is to validate the resulting synoptic catalogue and to use it in daily weather forecasting systems.

\subsection{Methodology to make the synoptic catalogue}

The PCA is applied in S-Mode (the variables are grid points columns - and the days are the observations - rows) and analysed individually for each of the variables considered (SLP, T850, Z500 and wind gust data). This analysis is used as an intermediate step in order to reduce the number of variables for later classification that uses CA (Huth et al., 2008). Traditionally, principal component analysis is performed on the symmetric covariance matrix or on the symmetric correlation matrix. We have worked with the correlation matrix and the Scree Test has been used as a criterion to determine the number of factors; that is to say, we cut just when it detects a change of slope in the sedimentation graph (Cattell, 1966; Huth, 1996). Finally, the varimax orthogonal rotation was applied to the factors, since this technique reduces the dependency between components and satisfies the orthogonality condition model based on a minimisation of the number of variables with a high loading factor (Richman, 1986).

The following step is to apply the CA to the scores of each of the four variables individually obtained by applying the PCA. We used the non-hierarchical K-means method. The main critical point of this technique is to decide the definitive number of clusters. So, firstly, to solve this problem we used the Jump method, which uses a hierarchical algorithm and applies the Ward method (Ward, 1963) as a technique of agglomeration (Aran et al., 2010). The coefficient given in the agglomeration process is the sum within the clusters. The number of groups is determined by detecting the greater distortion of the coefficients in two consecutive steps. Secondly, once the number of clusters was decided, the K-Means method without iterations was applied in order to avoid the tendency to equalise the size of the groups in which case the result may not be realistic (Huth et al., 2008).

The DA is the third and final step to validate this methodology and it proposes a new classification for doubtful cases. Fisher's linear discriminant method is applied to obtain the discriminant functions (Fisher, 1936). Previously, the selection of the independent variables contributing to distinguish between different clusters is obtained applying the Wilks' lambda criterion (Sioutas and Floucas, 2003). In this process, the factors of the PCA scores are used as predictors, and each event is assigned to a synoptic type according to 


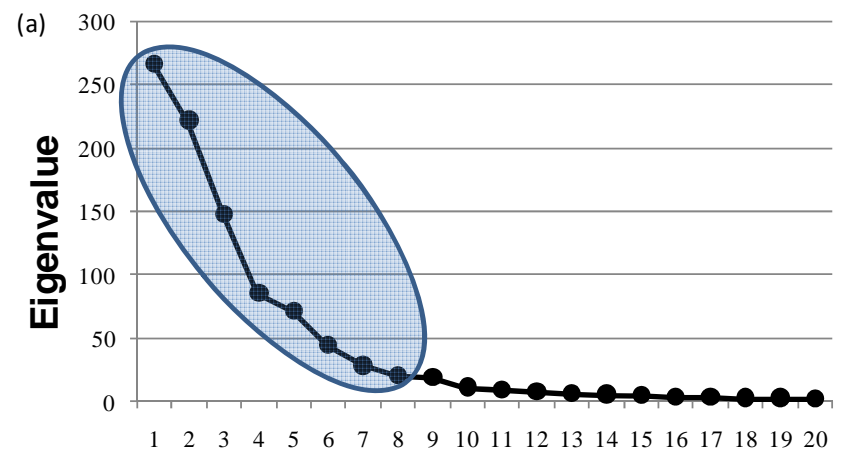

Component number

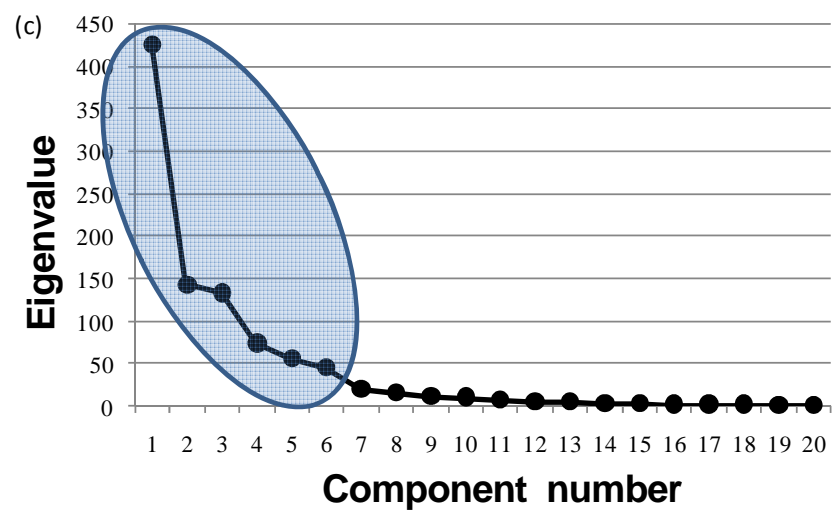

Fig. 4. Scree test of the eigenvalues obtained from each grid: (a) to one significant slope change.

the scores obtained from the discriminant functions. Finally, a cross-validation process is used for the new classification. This process consists of taking an event and classifying it using the discriminant functions derived from all other cases. In the next subsection it is explained how these functions are used to classify events not included in the original database.

\subsection{Methodology to classify new events}

This section presents how to use the methodology explained in Sect. 3.1 to classify a strong wind event from the validation period.

Firstly, it is necessary to standardise the four matrices (variables) used in the original classification (SLP, T850, Z500 and VV). The standardisation is carried out spatially, that is, by column, as they have an order in S-Mode. We will use the mean and standard deviation of each column, i.e., each grid point $j$, to standardise the news days $i$ from the validation period.

The Eq. (1) is used to estimate the scores $\left(P_{i f}\right)$ for each day $(i)$ and for each of the four standardised variables analysed

$P_{i f}=\sum_{j=1}^{N} C_{i j} V_{j f}$.

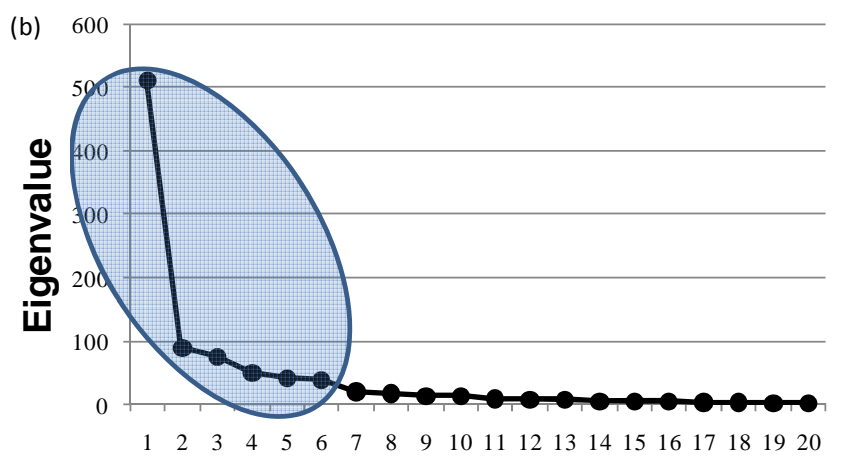

Component number

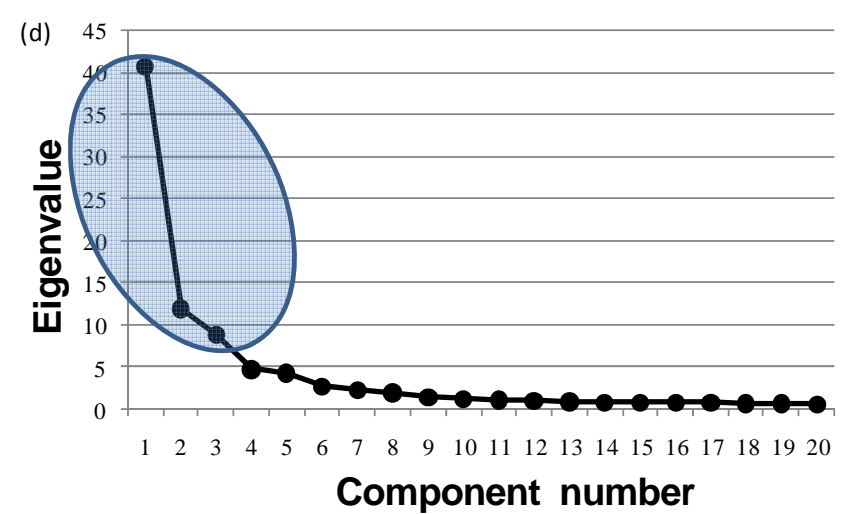

, (b) T850, (c) Z500 and (d) Wind Velocity. Shaded area corresponds where $N$ is the total number of grid points $j, C_{i j}$ is the standardised variable and $V_{j f}$ is the component score coefficient of the factor $f$ of the variable analysed in each grid point $j$.

Once the scores are known $\left(P_{i f}\right)$ for each variable, the discriminant functions are used to classify this day in the respective synoptic pattern. Each cluster has its corresponding Fisher's discriminant function (see Sect. 3.1). For each cluster, punctuations are computed according to Eq. (2) defined as

$F_{\mathrm{CL}}=a_{1} P_{1 i}+a_{2} P_{2 i}+\ldots .+a_{n} P_{n i}+c$.

where for a day $i, F_{\mathrm{CL}}$ is the discriminant punctuation for one of the clusters CL, $a_{n}$ are the coefficients corresponding to the Fisher linear discriminant function for that cluster and $c$ is a constant term. For each day, the cluster with maximum discriminant punctuation is chosen as the more relevant synoptic type.

\section{Results}

\subsection{Principal Component Analysis}

The PCA is used as an intermediate tool for data reduction. The procedure is applied to every four datasets and an Smode data matrix is used. Eight factors were retained for 


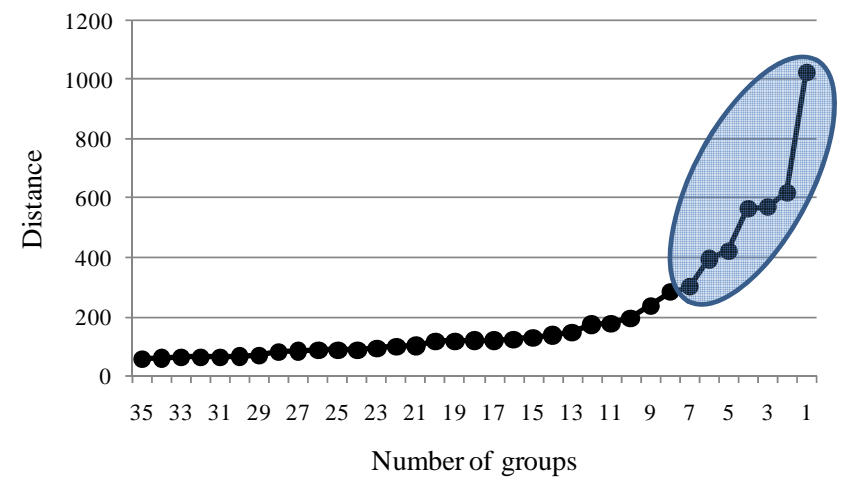

Fig. 5. Scree test of the distance between consecutive coefficients obtained from the agglomeration schedule. The shaded area corresponds to one significant slope change.

SLP grid using Scree test criterion (Fig. 4), six factors for T850 and Z500 grid, and, finally, three factors for the gust wind matrix. Then, Orthogonal Varimax procedure is used for rotating the components. It redistributes the variance explained among the rotated components. Thus, for SLP grid, $90 \%$ of the total variance is explained by the eight components retained, $82 \%$ for the T850 grid, $90 \%$ for the Z500 grid and $56 \%$ for the wind matrix. As can be seen, the three wind factors explain a very low variance. This can be explained by the complex topography of Catalonia and when taking more factors, the result did not improve.

\subsection{Cluster Analysis}

CA is applied to the factor score matrix, comprised of each of the four individual factor scores resulting from the PCA. The number of groups required for clustering was decided by applying the "jump method", so that, from the analysis of the coefficient given in the agglomeration schedule, the total number of groups can be 7 (Fig. 5). Then, the K-means procedure is applied without iterations with the goal of classifying the 569 strong wind events into seven predefined clusters.

\subsection{Discriminant Analysis}

DA was applied in order to validate the model. The low value of the Wilks' lambda $(\lambda=0.009)$ shows that the model is able to discriminate and re-classify the strong wind events correctly in the seven synoptic patterns defined in the CA. The model showed that $94 \%$ of original grouped cases were correctly classified and the cross-validation result was that $89 \%$ of the original cases were well classified. These values were good enough and encourage us to use this classification to define the most important synoptic patterns that explain high impact wind events over the study area.
Table 2. Frequency (in \%) of strong wind events for each cluster and for the MEDEX and validation periods.

\begin{tabular}{ccc}
\hline Cluster & MEDEX period & Validation period \\
\hline C1 & 16.7 & 8.6 \\
C2 & 16.7 & 5.5 \\
C3 & 16.5 & 25.7 \\
C4 & 14.2 & 11.3 \\
C5 & 22.7 & 14.1 \\
C6 & 7.0 & 29.4 \\
C7 & 6.2 & 5.5 \\
\hline
\end{tabular}

\subsection{Synoptic patterns}

Figure 6 shows the main characteristics of the seven patterns obtained. In the first column, the mean values within each geopotential pattern at $500 \mathrm{hPa}$ in geopotential metres (shaded) and mean sea level pressure in $\mathrm{hPa}$ (solid lines) are presented and in the second column temperature at $850 \mathrm{hPa}$ is shown in ${ }^{\circ} \mathrm{C}$. Although it did not seem that the T850 was suitable to to analyse wind events, it has been proved as a determining factor to discern seasonal patterns. In order to understand a little bit more the affected areas in a pattern, the third column presents the percentage of strong wind days compared to the total number of days in each AWS. Finally, the monthly distribution of each pattern can be seen in the fourth column. In order to evaluate the spatial impact of a synoptic pattern, Fig. 7 shows the total number of AWS for all the events included in each cluster that has recorded a wind gust threshold in the different periods. These seven synoptic patterns are described in the following subsections. The frequency of strong wind events for each cluster is presented in the first column of Table 2.

\subsubsection{Cluster 1: northeast flow (NE)}

This first cluster is quite frequent with $17 \%$ mainly during winter, late autumn and early spring (Fig. 6, fourth column). The anticyclone is situated over the Northwest of the Iberian Peninsula, and its axis is oriented from West to East and it extends to central Europe. The presence of a low in southern Italy increases the pressure gradient in the north-eastern regions of Catalonia, where the strongest winds are recorded. The main regions affected are situated in the northern part of the region.

\subsubsection{Cluster 2: west-northwest flow (WNW)}

Although the frequency and a seasonal distribution of this second cluster are very similar to the NE-Flow, its characteristics are completely different. The anticyclone is situated over the Azores islands. The main flow over the central and northern parts of Europe is westerly and also affects 


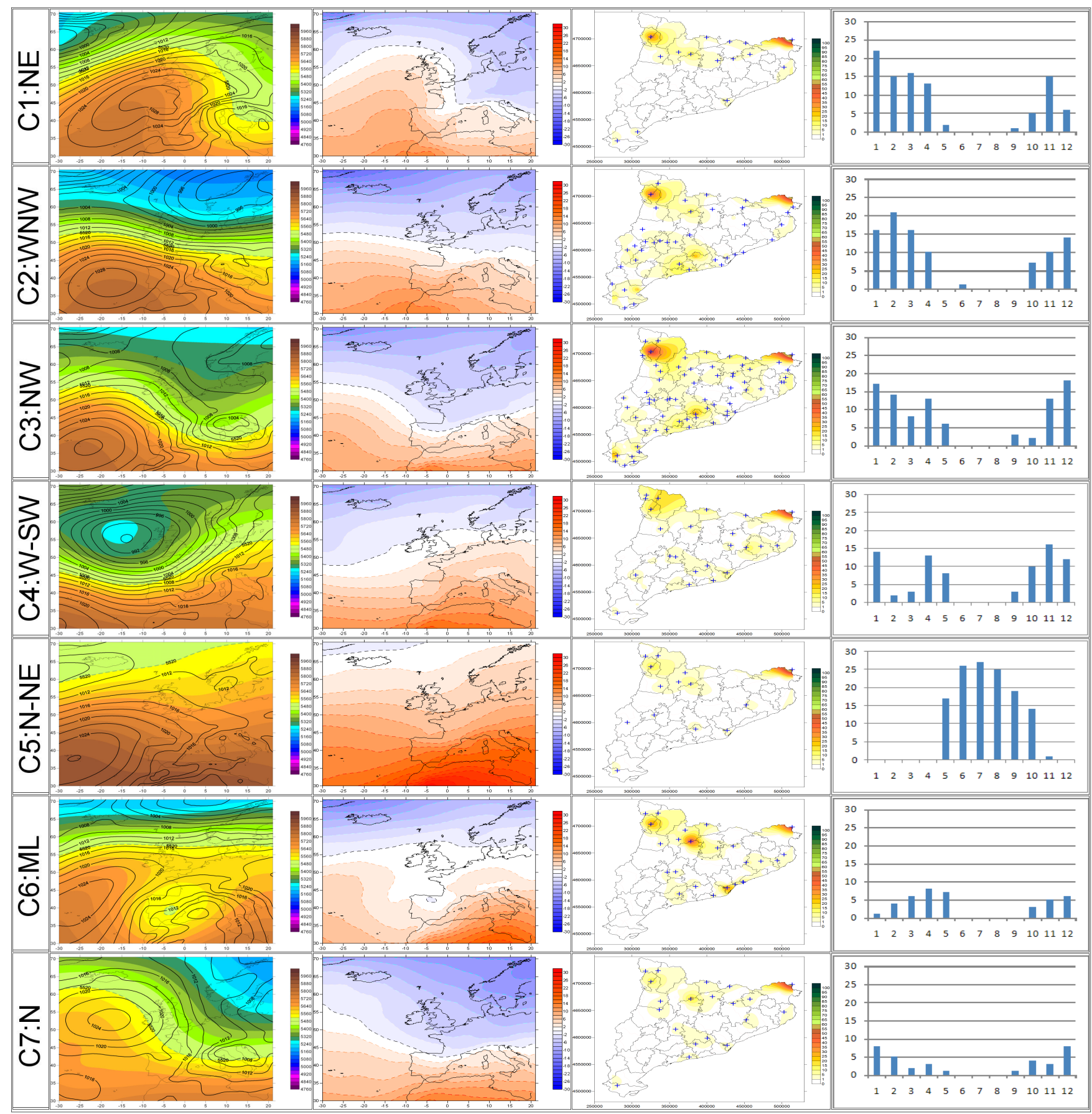

Fig. 6. Mean values of ERA-Interim reanalysis for each cluster (see acronym in Sect. 4.4). First column, geopotential at $500 \mathrm{hPa}$ in mgp (shaded) and mean sea level pressure in $\mathrm{hPa}$ (solid lines). Second column, temperature at $850 \mathrm{hPa}$ in ${ }^{\circ} \mathrm{C}$ (shaded). Third column, $\%$ of strong wind days with respect to the total number of days in the cluster. Fourth column, monthly distribution of the number of strong wind events.

the Iberian Peninsula. In Catalonia, most of the regions are affected yet in the downwind regions of the northern Prelitoral range where altitudes are higher (some peaks higher than $1700 \mathrm{~m}$ ). This is the second pattern with more AWS that has exceeded the threshold of $20 \mathrm{~m} \mathrm{~s}^{-1}$.

\subsubsection{Cluster 3: northwest flow (NW)}

This pattern is similar to the second one but the main pressure centres are more intense. Consequently, the pressure gradient is higher and the intensity of the events is greater and the whole region can be affected except for the downwind 

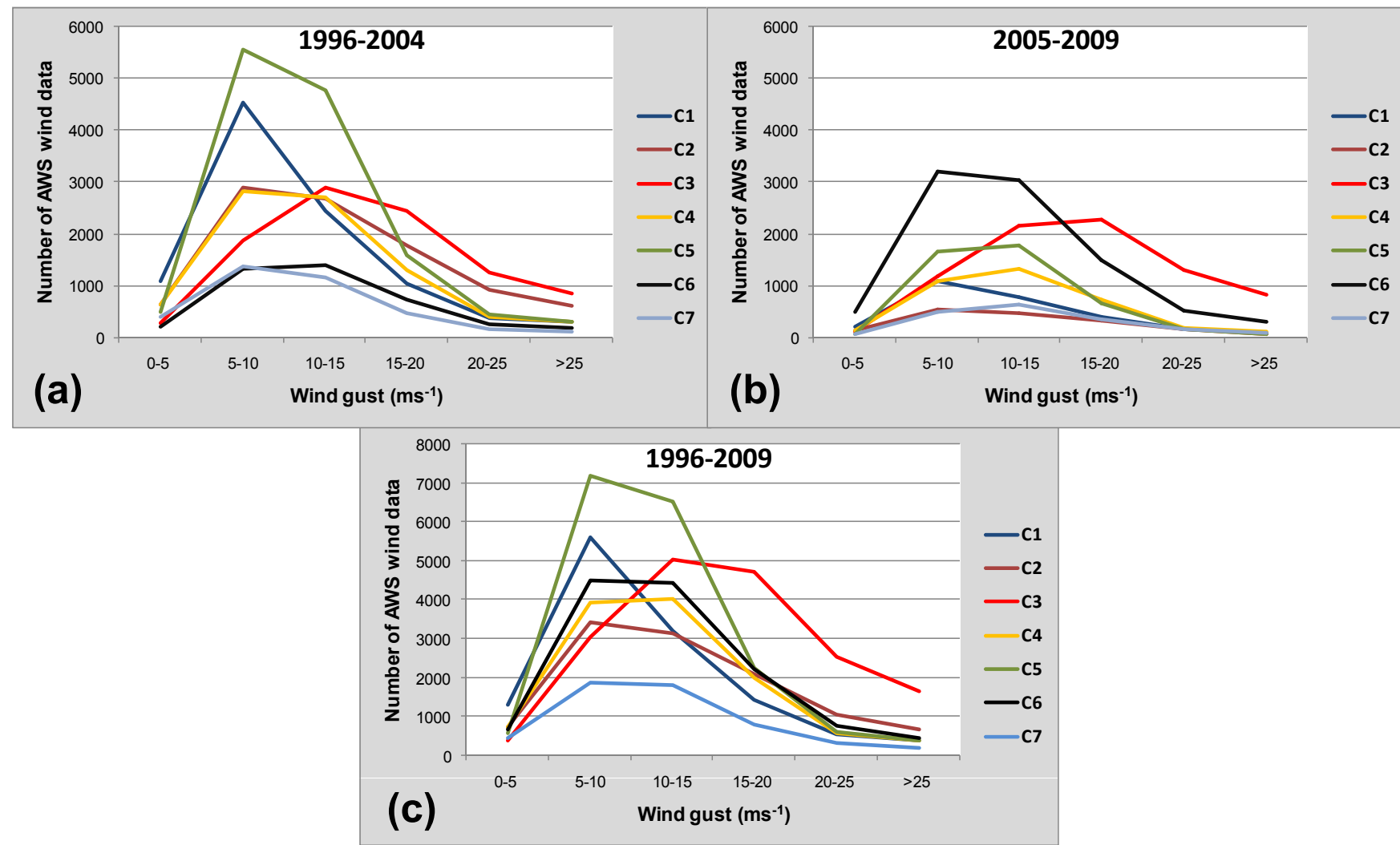

Fig. 7. Total number of AWS for all the events included in each cluster and gust intensity threshold (in $\mathrm{m} \mathrm{s}^{-1}$ ): (a) MEDEX period, (b) validation period, (c) the whole period of the database.

regions of the Pyrenees (low areas of the Pre-Pyrenees range). These situations are frequent in winter, spring and late autumn.

\subsubsection{Cluster 4: west-southwest flow (W-SW)}

The frequency of this pattern is $14 \%$ and it is more likely to occur in autumn and late spring. The intensity of these events strongly depends on the position of the Irish low, which is quite variable. Consequently, the extension affected is different from one situation to another but in general it affects only the AWS located up to $600 \mathrm{~m}$ in the Pyrenees or the Prelitoral range.

\subsubsection{Cluster 5: north-northeast flow (N-NE)}

This pattern corresponds entirely to summer and early autumn. It justifies the use of the temperature at $850 \mathrm{hPa}$ as it has been crucial to discern the seasonal character of strong wind events. Although this situation is very frequent (23\%), the number of regions affected by strong wind events are very low and correspond to higher altitudes or at both ends of the Catalan coast because of the dipole effect (Campins et al., 1995). On the other hand, this situation is the one with highest percentage of AWS with gusts exceeding $10 \mathrm{~m} \mathrm{~s}^{-1}$ (Fig. 7a).

\subsubsection{Cluster 6: Mediterranean Low (ML)}

The low is situated nearby the Balearic Sea. In these locations wind directions are quite variable and wind gust can be important because in some events they might be associated with heavy showers. This situation is not very frequent $(7 \%)$. However, when the low is located in the Balearic Sea, it may cause important structural damage to the coastal population and sea wave erosion.

\subsubsection{Cluster 7: north flow (N)}

The centre of the anticyclone is at high latitudes, west of Ireland, and the low, located in the North of Italy, is associated with the passing of a frontal system (the trough is over central Europe). In Catalonia, this front can take affect everywhere but it is more likely in the northern areas (the Pyrenees and the northern end of the Catalan coast) but these areas are locally affected (there are few AWS with wind, see Fig. 7a). 
Table 3. Predicted percentage of the clusters obtained from the discriminant analysis. Diagonal values correspond to correctly classified events, and the remaining values across a row the misclassified ones.

\begin{tabular}{cccccccccc}
\hline \multirow{2}{*}{ Cluster } & \multicolumn{7}{c}{ Predicted Group membership } & $\begin{array}{c}\text { Misclassified } \\
\text { events (\%) }\end{array}$ & $\begin{array}{c}\text { Number of strong } \\
\text { wind events }\end{array}$ \\
\cline { 2 - 6 } & $\mathrm{C} 1(\%)$ & $\mathrm{C} 2(\%)$ & $\mathrm{C} 3(\%)$ & $\mathrm{C} 4(\%)$ & $\mathrm{C} 5(\%)$ & $\mathrm{C} 6(\%)$ & $\mathrm{C} 7(\%)$ & 11 & 28 \\
\hline 1 & 89 & & & & & 11 & & 12 & 18 \\
2 & & 88 & 6 & & & 6 & & 13 & 84 \\
3 & & 4 & 87 & 2 & 1 & 4 & 2 & 9 & 46 \\
4 & & & & 92 & 3 & 6 & & 2 & 96 \\
5 & 2 & & 3 & 2 & 1 & 92 & & 8 & 18 \\
6 & 2 & 6 & 6 & & & 6 & 82 & 18 & \\
7 & & 6 &
\end{tabular}

\subsection{Classification results for the period 2005-2009}

In order to classify the strong wind events recorded in the period 2005-2009, we used the component score coefficient matrix, obtained from applying PCA, and Fisher's Linear from DA. The results show that, of the 327 new events, $91 \%$ have been well classified. After applying the cross validation process the result obtained is $85 \%$. These high percentages corroborate the adequacy of the proposed methodology.

Table 3 shows the percentage of events that are well classified (central diagonal matrix) and the percentage of events incorrectly classified for each cluster (rows). The correctly classified events vary from $98 \%$ for cluster 5 (C5) to $82 \%$ for cluster 7 (C7). On the other hand, in $\mathrm{C} 111 \%$ of the days are misclassified, and they move into the cluster $6 ; 12 \%$ of misclassified events in $\mathrm{C} 2$ are reclassified in $\mathrm{C} 3$ and $\mathrm{C} 6 ; 13 \%$ of the days in $\mathrm{C} 3$ misclassified are distributed between the $\mathrm{C} 2$ and $\mathrm{C} 6 ; 8 \%$ of $\mathrm{C} 4$ are moved to $\mathrm{C} 5$ and $\mathrm{C} 6 ; 2 \%$ of $\mathrm{C} 5$ moves to $\mathrm{C} 6 ; 8 \%$ of $\mathrm{C} 6$ is divided between $\mathrm{C} 1, \mathrm{C} 3, \mathrm{C} 4$ and $\mathrm{C} 5$; and finally $18 \%$ of the days misclassified in $\mathrm{C} 7$ are moved to $\mathrm{C} 2$, C3 and C6.

The second column of Table 2 shows the percentage of events for each cluster for the validation period. There are great differences compared to the distribution obtained with the MEDEX period (first column). Clusters 6 and 3 have increased considerably. On the other hand, Fig. 7b shows the number of AWS affected in each cluster according to a threshold. For the validation period the results are not so different compared to those obtained using the MEDEX period (Fig. 7a). The main difference can be found in cluster 7 where more AWS are affected, but this fact is correlated by the increased number of events. Something similar can be said with respect to cluster 3 . Although cluster 2 has decreased its frequency (5.5\%) for the whole period (19962009), the number of AWS exceeding $20 \mathrm{~m} \mathrm{~s}^{-1}$ is greater than the rest of the clusters, except cluster 3 (Fig. 7c). This result is interesting since it highlights the fact that the NWflow pattern is the most dangerous one.

\section{Conclusions and discussions}

This study presents a methodology based on multivariate analysis to build a catalogue of extreme events such as strong wind episodes. The methodology consists of applying a principal component, cluster and discriminant analyses to 4 meteorological variables, 3 of them in a synoptic-scale matrix (mean sea level pressure, geopotential at $500 \mathrm{hPa}$, temperature at $850 \mathrm{hPa}$ ) and one of them in a mesoscale matrix (wind gust from automatic weather stations).

Two different periods were classified independently in order to evaluate the goodness of the technique. With the first period (1996-2004), apart from obtaining the catalogue for strong wind events in Catalonia, we obtained the main scores and discriminant functions necessary for classifying any strong wind event. With the validation period (20052009) we assessed the plausibility of the methodology to classify a strong wind event in the catalogue obtained in the first phase.

One of the main disadvantages of using PCA and CA is that the previous studies did not take into consideration the relationships between the synoptic-scale circulation and local extreme events (Cassano et al., 2006). In this work, we have presented a methodology that uses local data (AWS wind data) to minimise this problem.

The patterns obtained are in concordance with previous studies (Font, 1983) and with our daily experience. NW flow (cluster 3) has been one of the most damaging events due to the confluence of the Azores Anticyclone and the passing of a deep low through the northern Iberian Peninsula, as happened on 24 January 2009 (Amaro et al., 2009a). On the other hand, it has been interesting to find a pattern related only to strong wind events in summer (cluster 5). Although the strength of these events is not as remarkable as others such as the NW pattern (cluster 3), this season is very critical because of the high number of tourism practising sea sports and the high number of rescue operations accomplished.

Finally, the complex topography leads the main flow in Catalonia. The general strong wind events in Catalonia are 
characterised by the presence of the Azores anticyclone over the west of Europe. In this case, the main wind gusts are in the northern region. However, when the Azores anticyclone is located more in the south the interaction of the synoptic flow with the Pyrenees develops a mesolow is developed in the Ebro Valley and the main wind is from the north-west at both ends of Catalan coast, as shown in clusters C2-WNW and $\mathrm{C} 3-\mathrm{NW}$.

The SMC is carrying out a study on how to use this methodology or the catalogue obtained, to implement an analogous forecast system and also its application to build a climatological classification.

Acknowledgements. The authors wish to thank the ECMWF for providing the ERA-Interim reanalyses. We are also grateful to Antoni Barrera-Escoda for his help in obtaining and converting the grid data and for his suggestions. We thank the anonymous referees for their useful comments, which have improved this paper.

Edited by: J. Salat

Reviewed by: two anonymous referees

\section{References}

Amaro, J., Aran, M., Barberia, L., and Llasat, M. C.: The Strong Wind event of 24th January 2009 in Catalonia: A social impact analysis, Proceedings of the 10th EGS Plinius Conference, Barcelona, Spain, 2009a.

Amaro, J., Gayà, M., Aran, M., and Llasat, M. C.: Preliminary results of the Social Impact Research group of MEDEX: requests related to Strong Wind events (2000-2002) of two Meteorological Services, Proceedings of the 10th EGS Plinius Conference, Barcelona, Spain, 2009b.

Aran, M. and Peña, J. C.: Atmospheric circulation patterns associated with hail events in Lleida (Catalonia), Preprints, 5th European Conference on Severe Storms, ECSS 2009, Landshut, available at http://www.essl.org/ECSS/2009/preprints/P03-05-aran. pdf, 2009.

Aran, M., Peña, J. C., and Amaro, J.: Atmospheric circulation patterns associated with strong wind events in Catalonia, Proceedings of the 11th Plinius Conference on Mediterranean Storms (Plinius-11), 2009.

Aran, M., Peña, J. C., and Torà, M.: Atmospheric circulation patterns associated with hail events in Lleida (Catalonia), Atmos. Res., in press, doi:10.1016/j.atmosres.2010.10.029, 2010.

Ávila, A. and Alarcón, M.: Relationship between precipitation chemistry and meteorological situations at a rural site in NE Spain, Atmos. Environ., 33, 1663-1677, 1999.

Beaver, S. and Palazoglu, A.: Influence of synoptic and mesoscale meteorology on ozone pollution potential for San Joaquin Valley of California, Atmos. Res., 43, 1779-1788, 2009.

Bénech, B., Koffi, E., Druilhet, A., Durand, P., Bessemoulin, P., Campins, J., Jansa, A., and Terliuc, B.: Dynamic Characteristics of Regional Flows around the Pyrénées in View of the PYREX Experiment. Part I: Analysis of the Pressure and Wind Fields and Experimental Assessment of the Applicability of the Linear Theory, J. App. Met., 37, 32-52, 1998.
Bougeault, P., Benech, B., Bessemoulin, P., Carissimo, B., Clar, A. J., Pelon, J., Petitdidier, M., and Richard, E.: PYREX: A summary of findings, B. Am. Meteorol. Soc., 78, 637-650, 1997.

Campins, J., Jansá, A., Benech, B., Koffi, E., and Bessemoulin, P.: PYREX Observation and Model Diagnosis of the Tramontane Wind, Meteorol. Atmos. Phys., 56, 209-228, 1995.

Campins, J., Jansà, A., and Genovés, A.: Heavy rain and strong wind events and cyclones in the Balearics, Adv. Geosci., 7, 7377, doi:10.5194/adgeo-7-73-2006, 2006.

Campins, J., Aran, M., Genovés, A., and Jansà, A.: High impact weather and cyclones simultaneity in Catalonia, Adv. Geosci., 12, 115-120, doi:10.5194/adgeo-12-115-2007, 2007.

Cassano, E. N., Lynch, A. H., Cassano, J. L., and Koslow, M. R.: Classification of synoptic patterns in the western Arctic associated with extreme events at Barrow, Alaska, Clim. Res., 30, 8397, 2006.

Cattell, R. B.: The scree test for the number of the factors, Multivar. Behav. Res., 1, 245-276, 1966.

Esteban, P., Jones, P. D., Martín-Vide, J., and Mases, M.: Atmospheric circulation patterns related to heavy snowfall days in Andorra, Pyrenees, Int. J. Climatol., 25, 319-329, 2005.

Esteban, P., Martín-Vide, J., and Mases, M.: Daily Atmospheric circulation catalogue for Western Europe using multivariate techniques, Int. J. Climatol., 26, 1501-1515, 2006.

Esteban, P., Ninyerola, M., and Prohom, M.: Spatial modelling of air temperature and precipitation for Andorra (Pyrenees) from daily circulation patterns, Theor. Appl. Climatol., 96, 43-56, 2009.

Fisher, R.: The Use of Multiple Measurements in Taxonomic Problems, Annals of Eugenics, 7, 179-188, 1936.

Font, I.: Climatología de España y Portugal, Sección de Publicaciones del Instituto Nacional de Meteorología, ISBN 84-5009467-4, 1983.

Gallero, F. J. G., Vallejo, M. G., Umbria, A., and Baena, J. G.: Multivariate statistical analysis of meteorological and air pollution data in the Campo de Gibraltar region, Spain, Environ. Monit. Assess., 119, 405423, 2006.

García, C., Martí, G., Oller, P., Moner, I., Gavaldà, J., Martínez, P., and Peña, J. C.: Major avalanches occurrence at regional scale and related atmospheric circulation patterns in the Eastern Pyrenees, Cold Reg. Sci. Technol., 59, 106-118, 2009.

García-Herrera, R., Díaz, J., Trigo, R. M., and Hernández, E.: Extreme summer temperatures in Iberia: health impacts and associated synoptic conditions, Ann. Geophys., 23, 239-251, doi:10.5194/angeo-23-239-2005, 2005.

Gaya, M., Amaro, J., Aran, M., and Llasat, M. C.: Preliminary results of the Societal Impact Research Group of MEDEX: the request database (2000-2002) of two Meteorological Services, Proceedings of the 9th EGS Plinius Conference, Nicosia, Ciprus, 2008.

González-Hidalgo, J. C., López-Bustins, J. A., Štepánek, P., MartínVide, J., and de Luis, M.: Monthly precipitation trends on the Mediterranean fringe of the Iberian Peninsula during the second half of the 20th century (1951-2000), Int. J. Climatol., 29, 14151429, 2008.

Houssos, E. E., Lolis, C. J., and Bartzokas, A.: Atmospheric circulation patterns associated with extreme precipitation amounts in Greece, Adv. Geosci., 17, 5-11, doi:10.5194/adgeo-17-5-2008, 2008. 
Huth, R.: Properties of the circulation classification scheme based on the rotated principal component analysis, Meteorol. Atmos. Phys., 59, 217-233, 1996.

Huth, R., Beck, C., Philipp, A., Demuzere, M., Ustrnul, Z., Cahynová, M., Kyselý, J., and Tveito, O. E.: Classifications of atmospheric Circulation Patterns. Recent Advances and Applications. Trends and directions in Climate Research, Ann. N.Y. Acad. Sci., 1146, 105-152, doi:10.1196/annals.1446.019, 2008.

Jiménez, P. A., Gonález-Rouco, J. F., Montávez, J. P., GarcíaBustamante, E., and Navarro, J.: Climatology of wind patterns in the northeast of Iberian Peninsula, Int. J. Climatol., 29, 501525, doi:10.1002/joc.1075, 2009.

Jorba, O., Pérez, C., Rocadenbosch, F., and Baldasano, J. M.: Cluster analysis of 4-Day Back Trajectories arriving in the Barcelona area, Spain, from 1997 to 2002, J. Appl. Meteorol., 43, 887-901, 2004.

Kohonen, T.: Self-organizing maps, 3rd edn. Springer Verlag, New York, 2001.

Kyselý, J. and Huth, R.: Relationships of surface air temperature anomalies over Europe to persistence of atmospheric circulation patterns conducive to heat waves, Adv. Geosci., 14, 243-249, doi:10.5194/adgeo-14-243-2008, 2008.

López-Moreno, J. I. and Vicente-Serrano, S. M.: Atmospheric circulation influence on the interannual variability of snow pack in the Spanish Pyrenees during the second half of the 20th century, Nord. Hydrol., 38(1), 33-44, 2007.

Martínez, C., Campins, J., Jansà, A., and Genovés, A.: Heavy rain events in the Western Mediterranean: an atmospheric pattern classification, Adv. Sci. Res., 2, 61-64, doi:10.5194/asr-261-2008, 2008.

Martin-Vide, J., Sanchez-Lorenzo, A., Lopez-Bustins, J. A., Cordobilla, M. J., Garcia-Manuel, A., and Raso, J. M.: Torrential rainfall in northeast of the Iberian Peninsula: synoptic patterns and WeMO influence, Adv. Sci. Res., 2, 99-105, doi:10.5194/asr-299-2008, 2008.

Moody, J. L.: The influence of meteorology on precipitation chemistry at selected sites in Eastern United States, PhD dissertation, University of Michigan, 176 pp., 1986.
Moody, J. L. and Gallowy, J. N.: Quantifying the relationship between atmospheric transport and the chemical composition of precipitation on Bermuda, Tellus, 40, 463-479, 1988.

Palutikof, J. P., Kelly, P. M., Davies, T. D., and Halliday, J. A.: Impacts of spatial and temporal wind speed variability on wind energy output, J. Appl. Meteorol., 26, 1124-1133, 1987.

Pineda, N., Esteban, P., Trapero, L., and Soler, X.: Circulation types related to lightning activity over Catalonia and the Principality of Andorra, COST Action 733 Mid-term Conference: Advances in weather and circulation type classifications \& applications, 2225 October 2008, Krakow, Poland, 2008.

Richman, M. B.: Rotation of Principal Components, J. Climatol., 6, 293-335, 1986.

Simmons, A., Uppala, C., Dee, D., and Kobayashi, S.: ERAInterim: New ECMWF reanalysis products from 1989 onwards, ECMWF Newsletter, 110, 25-35, 2007.

Sioutas, M. V. and Flocas, H. A.: Hailstorms in Northern Greece: synoptic patterns and thermodynamic environment, Theor. Appl. Climatol., 75, 189-202, 2003.

Vicente-Serrano. S. M., Beguería, S., López-Moreno, J. I., El Kenawy, A. M., and Angulo, M.: Daily atmospheric circulation events and extreme precipitation risk in the Northeast Spain: the role of the North Atlantic Oscillation, Western Mediterranean Oscillation, and Mediterranean Oscillation, J. Geophys. Res., 114, DO8166, doi:10.1029/2008JD011492, 2009.

Ward, J. H.: Hierarchical grouping to optimize an objective function, Journal of the American Statistics Association, 58, 236244, 1963.

Weber, R. and Furger, M.: Climatology of near-surface wind patterns over Switzerland, Int. J. Climatol., 21, 809-827, doi:10.1002/joc.667, 2001.

Yarnal, B.: Synoptic climatology in environmental analysis, Belhaven Press, London, 195 pp., 1993. 